\section{Multiple finger joint replacement and continuous physiotherapy using ultrasound guided, bilateral infraclavicular catheters for continuous bilateral upper extremity analgesia}

TABLE

\begin{tabular}{lllllll}
\hline Time & $0-24$ & $24-48$ & $48-72$ & $72-96$ & $96-120$ & $120-126$ \\
& $h r$ & $h r$ & $h r$ & $h r$ & $h r$ & $h r$ \\
\hline $\begin{array}{l}\text { Total } \\
\text { ropivacaine }\end{array}$ & $762 \mathrm{mg}$ & $675 \mathrm{mg}$ & $606 \mathrm{mg}$ & $600 \mathrm{mg}$ & $356 \mathrm{mg}$ & $0 \mathrm{mg}$ \\
$\begin{array}{l}\text { Pain scores } \\
\text { minimum/ }\end{array}$ & $2 / 6$ & $0 / 5$ & $0 / 2.5$ & $0 / 2$ & $0 / 2$ \\
maximum
\end{tabular}

*Pain score is on a scale of $0-10$.

given in the Table. The highest pain score occurred at the time the CPM was initiated.

The patient returned home on the evening of POD five following removal of both catheters. At the end of three months, she was doing well with regular follow up in the chronic pain clinic.

Bilateral infraclavicular catheter insertion has previously been reported; $;^{1,2}$ however, both catheters were not being used to provide simultaneous postoperative pain relief. Open surgery of both hands required a large volume of LA; therefore, ropivacaine was chosen because of its greater margin of safety. Ultrasound facilitated the accurate localization of the plexus and thereby reduced the volume and concentration of LA. Epinephrine was added as an intravascular marker. The second catheter was inserted within a few minutes of the first; however, in order to limit the peak plasma concentrations that may occur $20-45$ min after a bolus administration, the LA was not administered simultaneously.

The catheter location can be confirmed with agitated D5W when the tip can be seen by colour Doppler. The injection of LA can be monitored under ultrasonographic visualization, and inadvertent intravascular injection can, thereby, be prevented. The patient was educated about the signs and symptoms of LA toxicity. She was looked after in a monitored care facility where intravenous access was maintained at all times.

The recommended safe single dose limit for peripheral nerve block with ropivacaine is $300 \mathrm{mg},{ }^{3}$ while continuous peripheral nerve block infusions of up to 28 $\mathrm{mg} \cdot \mathrm{hr}^{-1}$ have been recommended. ${ }^{A}$ Cumulative doses of $770 \mathrm{mg}$ ropivacaine administered over $24 \mathrm{hr}$ have been well tolerated in adults when used for postoperative pain management. ${ }^{4}$ Bilateral blocks of any kind must be evaluated on a case-by-case basis, and concerns regarding toxicity must be carefully addressed.

\footnotetext{
A AstraZeneca Product monograph. NDA 20-533/S-012 pages
} 3-23. 
Shalini Dhir MD

Sudha Singh FRCPC

John Parkin

Fadi Hannouche MD

Robert S. Richards FRCPC

St. Joseph's Health Care, University of Western

Ontario, London, Canada

Conflict of interest: None.

E-mail: shalini.dhir@sjhc.london.on.ca

Accepted for publication September 2, 2008.

\section{References}

1 Sandhu NS, Maharlouei B, Patel B, Erkulwater E, Medabalmi $P$. Simultaneous bilateral infraclavicular brachial plexus blocks with low-dose lidocaine using ultrasound guidance. Anesthesiology 2006; 104 : 199-201.

2 Franco $C D$, Salabuddin $Z$, Rafizad $A$. Bilateral brachial plexus block. Anesth Analg 2004; 98: 518-20.

3 Simpson D, Curran MP, Oldfield V, Keating GM. Ropivacaine: a review of its use in regional anaesthesia and acute pain management. Drugs 2005; 65: $2675-$ 717.

4 Owen MD, Dean LS. Ropivacaine. Expert Opin Pharmacother 2000; 1: 325-36.

\section{Awake orotracheal intubation under airway topical anesthesia using the Bonfils in patients with a predicted difficult airway}

To the Editor:

The Bonfils Retromolar Intubation Fibrescope ${ }^{\mathrm{TM}}$ (BRIF ${ }^{\mathrm{TM}}$; Karl Storz Endoscopy, Tuttlingen, Germany) is a semi-rigid optical stylet with an outer diameter of $5.0 \mathrm{~mm}$, a fixed anterior tip curvature of $40^{\circ}$, and a $1.2-\mathrm{mm}$ working channel. ${ }^{1}$ Successful intubation using the BRIF ${ }^{\mathrm{TM}}$ has been confirmed in patients with predicted or known difficult airways, either awake or under general anesthesia. ${ }^{2,3}$ We recently assessed the efficacy of the BRIF ${ }^{\mathrm{TM}}$ for airway topical anesthesia and awake intubation in patients with predicted difficult airways.

After obtaining local Ethics Committee approval and written informed consent, 45 patients aged 18$67 \mathrm{yr}$, weighing $56-68 \mathrm{~kg}$, and scheduled for elective surgery were included in the assessment. The patients were predicted as having a difficult airway due to the following factors: a limited mouth opening with an inter-incisor distance of $17-30 \mathrm{~mm}$ ( 11 cases), limited head and neck movement ( 21 cases), a Mallampati grade 4 with a history of severe snoring when sleeping in the supine position (eight cases), and micrognathia with a thyromental distance $\leq 5 \mathrm{~cm}$ (five cases). Our anesthetic plan was to perform awake intubation in all cases using the BRIF ${ }^{\mathrm{TM}}$ under airway topical anesthesia prior to general anesthesia.

According to methods previously described, ${ }^{4}$ we placed an end-hole epidural catheter in the working channel via the injection port of the BRIF ${ }^{\mathrm{TM}}$, with the distal tip of the epidural catheter close to the distal end of the BRIF ${ }^{\mathrm{TM}}$ but not protruding beyond. This was attached proximally to a triple stopcock and an oxygen supply of $2 \mathrm{~L} \cdot \mathrm{min}^{-1}$. Lidocaine was injected via the triple stopcock and emerged distally as a fine spray. In the preoperative holding area, a $20 \mathrm{G}$ intravenous cannula was inserted, standard monitors were applied, and atropine $0.3-0.5 \mathrm{mg} i v$ was administered for its antisialogogue effect. The posterior pharynx was anesthetized with five intra-oral sprays using a metered-dose inhaler of $10 \%$ lidocaine (Astra ${ }^{\circledR}$ Pharmaceutical Products, Inc, Westborough, MA, USA); each depression of the release button delivered $0.1 \mathrm{~mL}$ $(10 \mathrm{mg})$. In the operating room, fentanyl $1.5 \mu \mathrm{g} \cdot \mathrm{kg}^{-1}$ $i \nu$ was administered, and midazolam was titrated in increments (up to $2-4 \mathrm{mg}$ iv) to establish to the desired level of sedation, i.e., with the patient calm, falling asleep if undisturbed, but still appropriately responding to verbal commands. With the patient's head and neck placed in a neutral position, a prepared BRIF ${ }^{\mathrm{TM}}$ was inserted into the patient's mouth in the midline, and slowly advanced into the airway until the epiglottis was reached. ${ }^{1}$ Next, $1 \mathrm{~mL}$ of lidocaine $2 \%$ was sprayed into the epiglottic vallecula under direct vision of the BRIF ${ }^{\mathrm{TM}}$, and this procedure was repeated after five minutes. After completion of the supraglottic spray, the BRIF ${ }^{\mathrm{TM}}$ was again inserted and positioned immediately anterior to the vocal cords. At this time, $2 \mathrm{~mL}$ of lidocaine $2 \%$ was sprayed to anesthetize the laryngotracheal area. This procedure was also repeated after five minutes. Five minutes after the second laryngotracheal spray, the BRIF ${ }^{\mathrm{TM}}$, preloaded with a 7.0 $\mathrm{mm}$ or $7.5 \mathrm{~mm}$ cuffed endotracheal tube (ET'T), was inserted and advanced towards the posterior pharynx until the tip of the scope just passed the glottic opening. An additional $2 \mathrm{~mL}$ of lidocaine $2 \%$ was injected into the trachea and the ETT was advanced over the BRIF ${ }^{\mathrm{TM}}$ into the trachea. An independent investigator scored the patient's reaction during intubation using a modified five-point scale (no reaction $=1$, slight gri- 